\title{
Quando a imagem é corpo: modos de sobreviver à máquina colonial
}

\section{When image is body: ways to survive the colonial machine}

Fernando Resende ${ }^{1}$

Roberto Robalinho ${ }^{2}$

Diego Granja Amaral ${ }^{3}$

Resumo: Este artigo parte dos vestígios de uma escrava africana enterrada na região portuária do Rio de Janeiro e do filme "Era o Hotel Cambridge" (Brasil, 2016), sobre uma ocupação no centro de São Paulo, com o objetivo de discutir como a imagem configura um corpo a partir de situações liminares. A proposta é observar a emergência intermitente das imagens e daquilo que é relegado à posição de resto, rastro, e vestígio na estrutura do poder colonial. Dos ossos humanos, que clamam um acerto com um passado escravagista, ao esqueleto de um edifício abandonado pela especulação e reinventado como corpo político por refugiados e sem-teto brasileiros, a imagem é a instância que conduz as demandas políticas no tempo. É a insistência de uma memória marginalizada, violentada, mas que recusa o apagamento. Como gesto de criação, persistência e (r)existência, a imagem nos serve como instrumento analítico para pensar contextos pós-coloniais e suas sobrevivências.

Palavras-chave: corpo; tempo; imagem; pós-colonial; sobrevivência.

Abstract: Having as a starting point the human remains of an African slave buried in Rio de Janeiro's harbour and the film "Era o Hotel Cambridge" (Brazil,

1 Universidade Federal Fluminense (UFF). Niterói, RJ, Brasil. https://orcid.org/0000-0002-7878-4840 E-mail: fernandoaresende1501@gmail.com

2 Universidade Federal Fluminense (UFF). Niterói, RJ, Brasil. https://orcid.org/0000-0001-7642-9805 E-mail: rrobalinho78@gmail.com

3 Universidade Federal Fluminense (UFF). Niterói, RJ, Brasil. https://orcid.org/0000-0002-1785-5131 E-mail: diegoamaral000@gmail.com 
2016), about a squat in downtown São Paulo, we will discuss how an image configures a body in extreme situations. We aim to observe the intermittent emergence of images and what is considered rest, trail and remains of colonial power structures. From human bones that claim reparation from their slave past, to the skeleton of an abandoned building reinvented as political body by refugees and Brazilian homeless, image is the instance that carries political demands in time. It is the insistence of a marginalized and violated memory that refuses to be erased. As a gesture of creation, persistence and re-existence, image becomes an analytical tool to understand postcolonial contexts and its surviving remains. Keywords: body; time; image; postcolonial; survival. 
482 QUANDO A IMAGEM É CORPO: MODOS DE SOBREVIVER À MÁQUINA COLONIAL

\section{A imagem em uma geografia exaurida}

Este artigo parte de duas experiências radicais de violência e aniquilação da vida para pensar como é possível fazer surgir, da lama inerte, um corpo, uma vida e uma imagem. Como uma forma de pensar nossa trajetória colonial, olharemos primeiro para os vestígios da escravidão: ossos encontrados na região portuária do Rio de Janeiro. Eles são restos que configuram uma imagem, e pensá-los é pensar a imagem e suas complexas camadas que, como nos indica Didi-Huberman, devem ser "entendidas ao mesmo tempo como documento e como objeto de sonho, como obra e objeto de passagem, como monumento e objeto de montagem, como não saber e objeto de ciência” (2012, p. 209). Ou seja, no porto do Rio, os ossos de africanos escravizados são o que não devia existir, são a imagem do inimaginável, a imagem de um genocídio que insiste em se fazer presente. Porém, conforme também veremos, através de múltiplos agenciamentos, eles encontram um caminho para superfície, tornando-se um corpo que existe apesar de tudo.

O olhar para os ossos, imagens que restam da escravidão, nos servirá, num segundo momento, para compreender como o filme "Era o Hotel Cambridge" (Eliane Caffé, Brasil, 2016) elabora também um corpo que se constrói a partir das sobras do capitalismo mundial. São os refugiados de diversos países e os sem-teto brasileiros, que sobre o abrigo de um hotel abandonado no centro da cidade de São Paulo, conseguem produzir uma experiência comum, desafiando os poderes constituídos. São nordestinos, congoleses, palestinos e mesmo enfermeiras, garis, eletricistas, auxiliares de escritório, entre tantos outros, que a Frente por Luta de Moradia chama no filme de "a base". Em condições de expropriação extrema, eles próprios se constituem como um corpo através do hotel e do próprio filme.

Os ossos, no Porto do Rio, os refugiados e o hotel, no filme, são aqui entendidos como operadores de invenção corporal e subjetiva, tributários não apenas da composição de um corpo, mas de uma imagem capaz de constituir um corpo, dilacerado, muitas vezes, através de múltiplos agenciamentos. Enquanto sobras, eles partilham de uma relação 
de poder que os subjuga a um grau zero subjetivo que podemos chamar de "precarização" (BUTLER, 2004).

Por este viés, a sugestão é pensar tanto a constituição de um corpo a partir dos ossos, como também o "ser refugiado" enquanto condição de resistência política, processo que passa pela articulação de uma imagem e pela reinvenção de um corpo, sendo ambos, ao mesmo tempo, sobrevivência à aniquilação e evidência de um processo histórico de extermínio simbólico e material. Parte do nosso objetivo é alinhar o pensamento em torno de um "processo de africanização do mundo", que Mbembe (2003) entende como sendo a precarização e a objetificação do outro, com o "Nós, os refugiados”, de Hannah Arendt (2013), em que a condição de apátrida do refugiado se torna uma condição histórica de vanguarda e abertura para compor qualquer outra e múltipla subjetividade.

Sob esta perspectiva, partimos da premissa de que diante de um mecanismo de poder colonial, do qual fazemos parte, e que tem por base a invenção e a dominação do outro, é possível, apesar de tudo (DIDI-HUBERMAN, 2003), produzir imagens do inimaginável. Isto posto, defendemos a hipótese de que é possível produzir um pensamento sobre nossa experiência colonial, a partir de uma reflexão de como as sobras, os rastros, as lacunas, as margens da máquina colonial, sejam elas ossos, sejam elas um filme sobre um hotel ocupado, configuram a todo momento imagens. Assim, propomos pensar esses restos inacabados a partir da imagem, uma vez que suas sobrevivências estão a todo momento, de forma intermitente, reverberando e produzindo outras imagens.

Irit Rogoff (2006) nos diz que o capitalismo global contemporâneo engendra "geografias exauridas", que exigem diferentes pensamentos, abordagens e outros instrumentos analíticos, distintos daqueles que as ajudaram a torná-las o que elas hoje são. Nessas geografias, entendemos, convergem, através de constantes disputas de poder, os restos inacabados da máquina colonial. E é deste mesmo chão destroçado, sugerimos, que brotam modos de vida que irão, à sua maneira, produzir fissuras, em um processo aberto que não se encerra. 
Nesse sentido, se a imagem é capaz de “criar ao mesmo tempo sintoma (interrupção no saber) e conhecimento (interrupção no caos)" (DIDI-HUBERMAN, 2012, p. 214), sugerimos que é a sua aparição no porto do Rio de Janeiro e sua conformação no filme de Caffé que também produz outras geografias. Isso nos exige atenção permanente e também nos permite dizer que com ela, a imagem, é preciso pensar. Por este caminho, mais do que escovar (BENJAMIN, 2008), o que buscaremos fazer é escavar a contrapelo as sobrevivências em torno do nosso maquinário colonial.

\section{Os ossos - ou o que resta do projeto colonialista}

A pesquisa etnográfica, realizada por Simone Vassallo (2017 e 2018), revela um processo complexo e múltiplo da descoberta de ossadas na região portuária do Rio de Janeiro. O ano é 1996, quando uma família de classe média inicia uma reforma em sua casa. Assim que o chão é quebrado, no meio dos escombros, sujeira, pedaços de tijolos e ossos começam a aparecer. A quantidade e a diversidade de fragmentos de ossos é tão impressionante, que surpreende a família que então interrompe todo o trabalho, suspeitando que ali, onde agora estava a casa, tivesse ocorrido uma chacina ou um assassinato em massa. Após investigar com os vizinhos a história do bairro, o casal chama os arqueólogos do Museu Nacional (RJ), que vieram inspecionar o local e recolher os ossos. A conclusão: ali jazia um antigo cemitério destinado ao depósito de ossos de negras e negros africanos. Traficados para o Brasil, eles eram todos recém-chegados - daí o nome "Pretos Novos" - que não conseguiram sobreviver à cruel travessia do Atlântico.

Esta descoberta colidiu, mais tarde, com os "Jogos Olímpicos de 2016", que promoveu um enorme processo de renovação urbana no porto da cidade do Rio. Entre outras ações, a reforma desvendou, por meio de escavações, o chamado "Cais do Valongo", antigo porto no qual desembarcaram, estima-se, cerca de 500 mil a um milhão de africanos escravizados destinados às Américas. Em meio ao lixo, os ossos na região do Valongo tornaram-se, desde então, uma parte da história colonial da 
cidade do Rio de Janeiro, a prova mais precisa do genocídio africano que ocorreu nas Américas.

Olhemos para a pilha de ossos que emergem do chão daquela casa como uma imagem da experiência colonial, o que, de acordo com Mignolo (2017), seria o "lado escuro" da modernidade. Para o autor, não é possível dissociar o processo de esclarecimento e a abundância material que marcam a fundação do projeto moderno sem conceber a descoberta da América, que se revelou não apenas uma abundante fonte de recursos materiais, mas também a base para um novo circuito comercial e, de forma igualmente importante, uma nova articulação das relações de poder-saber.

Nos termos de Mignolo (2005), a emergência do circuito comercial do Atlântico é o evento que funda o imaginário do chamado "mundo moderno/colonial”. Apoiado em Glissant (1997), que entende imaginário como uma construção simbólica a partir da qual uma comunidade - racial ou nacional, por exemplo - se define a si mesma, Mignolo oferece ao termo "imaginário" um artifício de "caráter geopolítico" (2005, p. 35). O que está em questão, para Mignolo, é a construção da ideia de um "hemisfério ocidental". Na sua perspectiva, o imaginário é, sobretudo, uma construção política que favorece a articulação de diferenças culturais em favor, por exemplo, de gestos de dominação racial, econômica e sexual.

Nesse sentido, ao se imaginar como branco, masculino e cristão, o "ocidente" se diferencia do restante do mundo que deseja dominar. E assim, o imaginário seria o elemento coesivo da ficção que se entende como "mundo ocidental". O ocidente, portanto, não representa aqui, uma noção estritamente geográfica. Na conotação geopolítica empregada por Mignolo, a exclusão da África, por exemplo, e, por conseguinte, a ideia do corpo negro como corpo do outro, é fundamental para a constituição deste imaginário. E nesse sentido, os vestígios de ossos não incorporam apenas a evidência da colonização, mas uma episteme moderna capaz de produzir restos ao moer os corpos negros. 
O circuito Atlântico também apresenta um caráter estratégico na articulação entre o imaginário político-social e a economia. E nesse sentido, "imaginar" o negro como outro, é parte de um projeto amplo de constituição das margens a serem exploradas pelo capitalismo, que começa a se consolidar juntamente com a modernidade. Também nesse processo começam a se produzir e articular imagens daquilo que é considerado indesejável, marginal, legado ao esquecimento ou ao apagamento (QUIJANO, 2005; MBEMBE, 2014). O projeto colonialista previa e demandava a existência de formas de dominação que seriam necessárias à sua subsistência, assim, é no cruzamento desses sistemas, que criam formas de vida, que o projeto escravagista também encontra acolhimento.

Hoje, a casa da família é o Instituto dos Pretos Novos (IPN), um lugar onde estão expostos os ossos que surgiram da terra. Na entrada, um texto descreve o que lá se encontra: uma pilha de ossos - de corpos negros descartados sem funerais, em valas ao ar livre junto com lixo, comida e restos de animais. Nesse sentido, os ossos expostos no chão de uma casa localizada no centro da cidade do Rio - este entulho que agora nos resta - são a sobra da máquina colonial. É deste entulho que vem à superfície a imagem do nosso horror; imagem reveladora da destruição em massa de corpos humanos, transformados em pedaços e poeira de ossos. Imagem que, como bem aponta Didi-Huberman, "se caracteriza por sua intermitência, sua fragilidade, seu intervalo de aparições, de desaparecimentos, de reaparições e redesaparecimentos incessantes" (2011, p. 86).

\section{O corpo, seu nome e a imagem que grita}

A extrema violência do genocídio africano no Brasil não está somente na aniquilação dos corpos, mas na tentativa constante de apagar a evidência do massacre. Esses corpos, e quaisquer outros remanescentes, não poderiam mais existir; como excrescências, são todos inimagináveis na opacidade da nossa modernidade. No entanto, em 2007, o arqueólogo Reinaldo Tavares decidiu raspar e escavar mais fundo o terreno do Instituto dos Pretos Novos (VASSALLO, 2018). Ao remover a terra a um 
metro de profundidade, para sua surpresa, onde apenas restos de lixo e pedaços de ossos pareciam existir, surge o esqueleto completo de uma jovem.

Exatamente ali, onde havia sido implementada uma política de obliteração dos corpos, naquele chão, onde antes era a vala de homens comuns e de onde hoje testemunhamos o massacre, há um corpo-imagem que nasce na intermitência que ela própria produz, imagem que nasce do esforço do seu próprio apagamento. Desta vez, os movimentos afro-brasileiros conseguiram proibir a remoção do esqueleto; ele lá ficou e está até hoje, no que a partir de então, através de um funeral religioso, passou a ser considerado o seu local de enterro.

Um dos arqueólogos deu ao esqueleto o nome da primeira santa negra e escrava: Josefina Bakhita ${ }^{4}$. Conforme registrado em uma entrevista feita por Vassallo (2018), o desejo de Tavares é que Josefina Bakhita possa gritar em voz alta para que todos ouçam e digam o que lá aconteceu. Como argumenta Rancière,

Tudo é rastro, vestígio ou fóssil. Toda forma sensível, desde a pedra ou a concha, é falante. Cada uma traz consigo, inscritas em estrias e volutas, as marcas de sua história e os signos de sua destinação (2009, p. 35).

Nesse sentido, é preciso ver e ouvir Josefina Bakhita. Seus ossos foram ressignificados e o seu esqueleto, exposto e emoldurado como um quadro que vemos ao olhar para o chão da casa, é a imagem que aqui incorporamos para ser, ela própria, tanto o testemunho do nosso genocídio quanto o desenrolar de outras travessias que nos nossos tempos também testemunhamos.

Sob essa perspectiva, nosso desafio é desvelar a história inscrita neste corpo-imagem que é, como sempre são as imagens, rastro. Afinal, inversamente, todo rastro, todo vestígio, todo fóssil é sintoma de uma trajetória e, portanto, de uma (outra) imagem. Como afirma Didi-Huberman,

4 Este processo, contudo, não se dá sem alguma ambiguidade, visto que se trata da reinserção do corpo da ex-escrava na ordem simbólica, justamente pela sua nomeação como santa católica (OLIVEIRA, 2017). 
Porque a imagem é outra coisa que um simples corte praticado no mundo dos aspectos visíveis. É uma impressão, um rastro, um traço visual do tempo que quis tocar, mas também de outros tempos suplementares - fatalmente anacrônicos, heterogêneos entre eles - que não pode, como arte da memória, aglutinar (2012, p. 216).

O esqueleto tem um rosto, uma história e um corpo - tudo o que entrelaça, afinal, uma imagem. Uma imagem do corpo, que agora está vivo como sujeito da própria imagem. Neste processo, que escolhemos chamar de "(r)existência”, a aparição de Josefina Bakhita é política, pois como imagem e corpo, ela incorpora as singularidades das existências de todos os corpos que foram com ela esmagados; uma existência agora articulada com os múltiplos agentes e acontecimentos que compõem o Cemitério dos Pretos Novos, no centro da cidade do Rio de Janeiro.

Ao pensar o processo imagético de aparição de um povo - o que para nós também significa a aparição de Josefina Bakhita -, Didi-Huberman afirma que ali se cria

espaço onde as relações entre as diferenças passam a se constituir, encenando um conflito permanente entre aquilo que Benjamin chamaria de 'barbarismo e cultura'. Conflito que relata, como em uma nova montagem perpétua de espaços e tempos, toda a história trágica da exposição e da disputa do humano (2014, p. 23).

Deste modo, o inimaginável presente na imagem de Josefina Bakhita é o intervalo que ela, a imagem, produz entre corpos e tempos: uma imagem tecida por um esqueleto, uma história, fragmentos de ossos, entulhos e cinzas; uma imagem que carrega um porto inteiro, uma cidade e um povo. Uma imagem, além de tudo, onde se configura um oceano, o Atlântico, que serviu de travessia de homens e mulheres rejeitados em seus próprios países, subalternizados e tratados como objetos precários no mundo do outro. É desta imagem, queremos sugerir, de sua própria intermitência - das histórias, das lutas, dos tempos e dos espaços que ela evoca - que partimos para pensar outras imagens, sobreviventes e 
resultantes do mesmo esforço de apagamento a que estão submetidos os sujeitos-excrescências - as sobras - do sistema mundo-moderno-colonial.

\section{O hotel - ou os corpos vivos na cidade de São Paulo}

Perseguindo os rastros das imagens que sobrevivem no/com o cinema, dirigimos nossa atenção ao filme Era o Hotel Cambridge (Eliane Caffé, 2016). Ao mostrar habitantes de um edifício abandonado fabulando sobre si mesmos diante da câmera, o filme torna impossível a separação entre a forma documental e a ficção, ativando um gesto que remete às potências do falso de Deleuze,

O que se opõe à ficção não é o real, não é a verdade que é sempre a dos dominantes ou dos colonizadores, é a função fabuladora dos pobres, na medida em que dá ao falso a potência que faz deste uma memória, uma lenda, um monstro (2009, p. 183).

Este filme, que trata de uma ocupação no centro da cidade de São Paulo, por parte de migrantes, refugiados e membros do Movimento Sem-Teto do Centro (MSTC), abre com um panorama sobre o centro da cidade. Aos poucos é que a câmera se deixa contaminar pelas pichações, pelos ruídos urbanos e pelo concreto cinza para depois se fixar em um dos prédios onde tremula a bandeira vermelha da Frente de Luta por Moradia (FLM). Após situar o espectador na cidade, a câmera dirige-se para o interior do edifício, onde vemos canos, fios e paredes rachadas que revelam, já de início, um dos personagens centrais do filme: o próprio edifício do antigo Hotel Cambridge ${ }^{5}$. Na iminência de desaparecer, é ele próprio que reaparece, no filme, como protagonista.

Como personagem, o edifício é quem costura e emoldura os diferentes corpos e vidas que nele se encontram. Ainda mais que isso, é nele (e com ele) que se torna possível a reunião de corpos tão distintos: são diversas línguas, pátrias e paisagens, ali mostradas a todo momento, através

5 Localizado na Avenida 9 de Julho, no centro de São Paulo, o Hotel Cambridge foi um dos grandes hotéis da região. Fundado nos anos 1950, época de importante crescimento da cidade, o hotel recebia hóspedes de todos os cantos do Brasil e do mundo. 
de quadros emoldurados pelas condições físicas e precárias do próprio hotel: escadas em espiral, janelas sem vidro, apartamentos apertados, um porão. É nesse conjunto de restos que o corpo do Hotel se torna o espaço de justaposição de diferenças.

Era o Hotel Cambridge enreda-se em um debate urgente e de grande abrangência. Seja colocando-nos diante do problema da (falta de) moradia nos grandes centros urbanos ou da própria questão relacionada às migrações e aos refúgios, o que este filme evoca, antes de tudo, é a precarização do humano. Ele trata da existência de corpos indesejáveis, de sobras que não cabem na utopia asséptica dos projetos modernos.

Em uma de suas cenas, em que alguns dos personagens reunidos em círculo discutem temas para uma atividade de improvisação, o congolês, Pitchou Luambo, sugere uma situação: "um menino em uma roda de avião”. Diante da perplexidade da plateia e do responsável por coordenar a atividade, o personagem explica tratar-se de um dado autobiográfico. Ele, Pitchou Luambo, em uma tentativa de fugir do conflito sangrento em seu país natal, agarrou-se a uma roda de avião; uma tentativa malsucedida que não fez com que Luambo desistisse da empreitada. Em outro momento, quando buscava migrar para os Estados Unidos, Luambo lançou-se no porão de um navio, o mesmo que o trouxe, sem que ele soubesse, ao Brasil. Repetindo de forma sintomática a trágica história de milhões de africanos, Luambo atravessa o Atlântico e chega, ainda que por forças distintas das que operavam no regime da escravidão, a uma terra desconhecida.

No Brasil, o congolês encontra outros indivíduos que, no processo de ocupação do Hotel Cambridge, partilham de sua mesma precária condição. Esse processo, que atravessa corpos, espaços e tempos, amalgamando memórias, disputas e formas de vidas precárias, é justamente o que vemos em Era o Hotel Cambridge. Este é um filme, conforme queremos demonstrar, cujas imagens, também intermitentes, produzem intervalos entre corpos e tempos, pois são compostas de uma história, de fragmentos de corpos e de entulhos, de muitas cidades e de muitos povos. Trata-se de um filme cujas imagens, além de tudo, reconfiguram 
oceanos inteiros que servem de travessia de homens e mulheres que, uma vez rejeitados em seus próprios países, são subalternizados e tratados como resto no mundo do outro.

Em outra cena do filme, também emblemática, um homem dirige seu olhar melancólico à tela do celular. Obedecendo ao toque do seu dedo, uma foto se move centralizando na tela o rosto de um menino sorridente. Sobrepondo-se à foto, há uma voz que diz: "Walikale, eu acho que você vai lá, mas presta atenção, tenha cuidado, porque, você sabe... tudo pode acontecer”. A partir daí, os dedos navegam por outras fotos, outras memórias de um casal, um grupo de amigos. A voz continua: "Se você descobrir, por exemplo, algo errado com o exército do Congo, entendeu? Você vai ter problemas".

Neste ponto, a tela abandona as reminiscências de uma vida aparentemente feliz, fazendo um corte para um grupo de homens negros trabalhando numa mina. Entra a voz que narra o círculo sangrento que envolve as Forças Democráticas Revolucionárias no Congo, os empresários que controlam as minas de coltan e estanho, e o conflito financiado pela exportação desses bens. Esta voz, agora corporificada em um homem que fala à luz de velas, nos conta que esses bens partem do Congo em direção a Ruanda e a outros países da África, seguindo então para a Europa, onde são usados na fabricação de telefones; o mesmo telefone que portava as fotos de um passado fragmentado. A narrativa continua com a imagem angustiante de um grupo de homens negros amontoados em uma mina escura. A única luz é a que sai dos seus capacetes e o som mistura falas na língua nativa com o ritmo estridente de ferramentas metálicas sobre as pedras.

O homem que vemos é então acordado pelo vizinho, após o que se revela ser um sonho. Fora do contexto da vida do personagem, contudo, as imagens remetem a paisagens não oníricas. Trata-se de um trecho do documentário Blood in the Mobile, de Frank Poulsen (Dinamarca/ Alemanha, 2010), que explora a relação entre a guerra no Congo, responsável pela morte de milhões de pessoas, e a exploração de minérios. 
O uso da intertextualidade, recurso para contar a história do refugiado congolês no Brasil, revela-se sintomático. De forma intermitente, entrelaçando tempos e espaços distintos, tanto a composição da cena em Era o Hotel Cambridge como no documentário de Poulsen, o que temos é o retorno, ou, mais precisamente, a continuidade do pesadelo colonial que pousa sobre os corpos tornados vulneráveis. Em ambos os casos, reconhecemos o fantasma da "colonialidade do poder" (QUIJANO, 2005), da espoliação dos corpos negros e de seus territórios; um processo cada vez mais intenso de distribuição global da desigualdade.

A imagem do homem negro que explora uma mina no Congo, portanto, é pertinente tanto em um documentário sobre a produção de celulares na Europa quanto no filme brasileiro que discute a precarização da vida em uma ocupação que abriga sujeitos em busca de moradia e em defesa dos seus direitos. O homem negro na mina é a imagem que toma lugar do próprio acontecimento, pois o que nela vemos é uma síntese dos processos de produção e relações de poder. Se o conflito no Congo, financiado pelo capital internacional, no processo de exclusão e produção de restos, é o próprio exercício da necropolítica (MBEMBE, 2003), esta imagem é, ela própria, o que resta do sistema de espoliação do outro.

Além disso, esta mesma imagem, cujo protagonista é um negro, referenda o raciocínio de Mbembe (2014), para quem, pela primeira vez na história, é nos nossos tempos que o termo "negro" deixa de se referir exclusivamente à origem africana, passando a nos remeter à condição máxima de uma vida vivida em estado de precarização, ou ainda, parafraseando Butler (2015), de uma vida precária, não passível de luto. O negro, nesse sentido, é o "migrante nu" (GLISSANT, 2008), aquele que é responsável por servir de mão de obra nas Américas e cuja memória de suas tradições e seus deuses se esvai progressivamente.

Tanto para Mbembe, como também o é para Glissant, o corpo negro é vítima de um processo violento de despossessão material e simbólica. Ele inaugura, podemos afirmar, uma violência subjetiva da qual o refugiado, nos dias atuais, torna-se herdeiro. Nesses nossos tempos, os corpos 
de refugiados congoleses, palestinos, venezuelanos, de sem-teto e favelados brasileiros, que se agrupam precariamente no Hotel Cambridge, são as Josefinas não batizadas do século XXI. Eles são corpos que tentam escapar da gestão da morte implementada pelo binômio Estado-capital, que é representado, no filme, pela ação da polícia que está sempre à espreita para cumprir o mandado de despejo.

Talvez a imagem mais emblemática dessa despossessão seja o gesto do refugiado palestino Isam Ahmad Issa, que em um sonho-lembrança varre as areias do deserto em um campo de refugiados na Jordânia. Logo depois de varrer a areia, ele se senta, deserto ao fundo, e fuma um cigarro com as pernas cruzadas. A imagem corta e ele está de novo no Hotel Cambridge, pernas também cruzadas e fumando um cigarro. A montagem propõe uma continuidade entre o deserto e o Hotel. Isam segue, em São Paulo como no deserto, varrendo as areias infinitas. A imagem de Isam, na Jordânia, tal qual a da mina no Congo, é um recurso intertextual usado no Era o Hotel Cambridge. Ela faz parte de outro documentário, A chave da casa, de Stela Grisotti e Paschoal Samora (Brasil, 2009), que mostra o mesmo personagem, Isam, na Jordânia, dias antes do seu embarque para o Brasil. Trata-se de mais um recurso que cria a mesma continuidade espacial do deserto ao Hotel. E não é só isso, pois é o mesmo corpo de Isam que atravessa os dois espaços. E é com esta imagem que vislumbramos a síntese do delírio moderno e, na generalização da sua condição de precariedade, a tradução mais exata da forma de dominação neoliberal.

Sob esta perspectiva, o refugiado se configura como um grupo de indivíduos forçados a deixar a sua condição de cidadãos em uma determinada sociedade para ocupar a posição de excluídos, de restos, em uma cultura radicalmente distinta. Ao transitarmos entre uma economia baseada na exploração da mão de obra humana, na indústria e no campo, e outra, baseada em algoritmos (MBEMBE, 2014), o que resta é o inimaginável de uma imagem que tem o precário - o infinito do deserto - como vetor. 
Nesse sentido, o que vemos é um processo de despossessão, que é, também e ao mesmo tempo, o processo de construção de uma subjetividade que diretamente evoca o processo econômico excludente da modernidade mundializada. Nas bordas da sociedade, o que temos é o sujeito relegado aos guetos, cujas vidas valem algo próximo a nada. Vidas que podem ser, e muitas vezes são, soterradas pela lama que não só garante a exportação de toneladas de ferro, como também a produção contínua da riqueza do outro.

Da escravidão ao refúgio (pensando a partir de instâncias espaço-temporais distintas), da bio- à necropolítica, da sociedade de controle (DELEUZE, 1992) à performance algorítmica neoliberal, o que resta - ou o que é comum - é o processo de subalternização e objetificação do outro. O que vemos, naquilo que é e "era o Hotel Cambridge", é um amálgama, um acúmulo desigual de tempos e corpos. Antes parte do cenário e também palco do próprio projeto colonialista, que nos anos 1950 inscrevia no corpo das grandes cidades a arquitetura, os ritmos e os sistemas de exclusão, o edifício do Hotel Cambridge, hoje com sua fachada marcada pelo abandono, suas pichações e rachaduras, seus fios e canos aparentes, se torna, no filme, o próprio corpo "sujo", a excrescência que ocupa e habita o centro da cidade de São Paulo.

Na economia moderna neoliberal, a miséria aproxima os restos e forçosamente amplia a noção de "refugiado". Ele passa a ser quem não tem nome, já que é ex-cêntrico, um sujeito que, por ser resto, por ser sobra, vive dentro, porém sempre nas bordas dos projetos neoliberais. Unidos pela "falta de direitos" - como, ainda na mesma assembleia, aponta Carmem Lúcia, personagem do filme e líder do Movimento dos Sem Teto - e amalgamados ao próprio edifício onde antes funcionava o hotel, estão os corpos decadentes e indesejados. Todos miseráveis, obrigados a formar novos corpos a partir da experiência que lhes é comum em torno do precário.

É esse corpo - e esses corpos - que o filme tece e reconfigura ao narrar a experiência de difícil harmonia entre a solidariedade - forçada pela precarização da vida - e a construção de outro modo de viver. Nas 
imagens que o filme produz estão os palestinos, os africanos e os nordestinos, todos sem teto. A despeito das diferenças que os habitam e que emergem na dura lida da convivência, o que resta é a vida precária, fragmentada e puída em vários fios que compõem e tecem um microcosmo enredado tanto nas imagens do filme, como na materialidade do próprio edifício.

É no gesto de ocupar o antigo hotel, entretanto, que essas "Josefinas sem nome” também se reconhecem e se autonomeiam. Quando reunidos em uma assembleia, dois dos seus moradores travam um diálogo no qual um deles, brasileiro, ao se opor a compartilhar o espaço com refugiados e migrantes, escuta de Isam Ahmad Issa: "Quero falar uma coisa", diz ele, apontando para si mesmo. "Eu sou refugiado palestino no Brasil", e prossegue apontando para o grupo, "vocês são refugiados brasileiros no Brasil". Nesta cena, outra das mais importantes do filme, Issa - personagem dele mesmo, já que é, na vida real, um refugiado palestino no Brasil - ao mesmo tempo em que sintetiza o problema contemporâneo da precariedade estrutural, propõe um nome que ofereça a eles a possibilidade da partilha e de constituição de uma comunidade.

Nas cenas finais, do lado de fora do edifício, os policiais, protegidos por escudos e capacetes, lançam bombas de gás lacrimogêneo inicialmente contra o prédio e posteriormente, na sequência apresentada pelo filme, contra os homens e mulheres que sobram e não cabem nas ruas do centro. Durante o confronto, uma série de imagens se empilha de forma avassaladora. No plano fílmico, há imagens internas ao hotel de pais e mães tentando proteger os filhos do gás lançado pela polícia. Por outro lado, a câmera, posicionada na rua, revela cocos atirados pelos moradores contra o batalhão.

Na transposição da batalha para a rua, cenas recorrentes de protestos nas grandes cidades, sobretudo nas cidades brasileiras, tomam forma. Manifestantes com rostos cobertos por camisetas atiram pedras contra policiais que passam a agir de forma menos articulada e mais focada em alvos específicos. Ônibus pegam fogo, vemos fumaça e prédios 
pichados, gerando imagens que parecem ser de qualquer lugar (ou de lugar nenhum).

Quem não luta tá morto, é o canto de guerra do FLM quando o choque chega para despejá-los. Nota-se que, dentro da narrativa, o choque chega quando o Hotel constitui uma comunidade na diferença, quando após uma série de desentendimentos, congoleses, nordestinos, palestinos e colombianos se afetam amorosamente, uns com os outros, apesar de não falarem a mesma língua. Luambo define o que é o amor em francês à menina brasileira; os dois se beijam. Gilda conta sua triste história ao jovem palestino que não sabe falar português, mas a conforta com uma canção de ninar em árabe, enquanto Lucia Pulido, pelo computador, canta uma música colombiana que emociona a todos que escutam.

Não importa mais as línguas singulares, as diferenças fazem parte desta nova comunidade de despossuídos que, para viver, precisam lutar. No gesto de resistência à invasão do Batalhão de Choque do Estado de São Paulo, nós os vemos unidos a favor dos seus próprios corpos e nomes, o que reforça a hipótese que levantamos: se são todos refugiados, é como refugiados-sem-teto que todos se articulam.

A imagem que precede o ataque do choque é o hotel visto por fora com os inúmeros corpos diferentes debruçados nas janelas. Esta é a imagem insuportável para o poder, a imagem de corpos vivos que perfazem uma comunidade de diferenças. É neste ponto que ao Estado não resta alternativa a não ser arrebentar esse corpo, como em outros tempos se arrebentava, como prática estatal, os corpos negros. E é assim que o Hotel, que era o Cambridge, se torna um corpo de corpos - diverso e de temporalidades e geografias densas, como também o é o corpo de Josefina Bakhita.

\section{Intermitência e (r)existência - uma imagem que nos olha}

Começamos com os ossos e esqueletos do genocídio negro no Brasil, chegando aos corpos, que ocupam um hotel no centro da cidade de São Paulo: não poderíamos dizer que esses fragmentos de tempos e espaços distintos, justapostos, reconfiguram a geografia de um Atlântico Negro 
(GILROY, 2017)? Mais ainda, como assistir a essas cenas de homens e mulheres que atiram pedras na tentativa de defender sua moradia, o seu território, sem nos lembrarmos das várias e mesmas imagens que vemos diariamente sobre a Palestina e seus territórios ocupados? Ao observar o desespero de homens e mulheres, majoritariamente negros e nordestinos, mas também africanos e árabes refugiados, amontoados, improvisando escadas para chegar ao teto do Hotel Cambridge, como não pensar nas poucas, mas densas imagens que temos dos navios negreiros ou mesmo nas muitas imagens sobre as guerras nas favelas que, através dos telejornais, invadem cotidianamente o nosso território?

Essas territorialidades, múltiplas, revelam e expõem subjetividades, corpos e temporalidades indesejadas, inimagináveis e esquecidas. A imagem que se forma, através dos múltiplos agentes que aqui apresentamos, incorpora e dá visibilidade a modos de existência destinados à invisibilidade. Mas antes, e a todo momento, são corpos e imagens que trazem à superfície passados indesejados e possíveis futuros de resistência. Deste modo, é na justaposição e na contraposição dessas multiterritorialidades (HAESBAERT, 2016), queremos pensar, que coexistem as estéticas, os afetos e os tempos desiguais.

Na intermitência dessas imagens, que vão e voltam, cruzando tempos e espaços distintos, é que nos parece possível encontrar as (r)existências. Elas são corpos - e os corpos são imagens - que teimam em emergir; são rastros e restos coletivos de pequenas ardências, chamas que acendem clareiras na escuridão. Como os vaga-lumes, esses corpos e essas imagens sobrevivem, de forma intermitente, desaparecem e tornam a aparecer, apesar de tudo (DIDI-HUBERMAN, 2011).

Assim, se de uma geografia exaurida (ROGOFF, 2006), como esta na qual estamos imersos, nasce a demanda por uma reflexão que busque recursos de outros instrumentos analíticos, este artigo, de algum modo, aposta na imagem como recurso fundamental no contexto das pós-colônias. O desafio é escavar a contrapelo a imagem que nos olha, de modo a fazer com que esta, enquanto instrumento analítico, possa também ser capaz de nos fazer ver. 
498 QUANDO A IMAGEM É CORPO: MODOS DE SOBREVIVER À MÁQUINA COLONIAL

\section{Referências}

AGAMBEN, G. Means without end: notes on politics. Minneapolis: University of Minnesota Press, 2000.

. O que resta de Auschwitz. São Paulo: Boitempo Editorial, 2008.

ARENDT, H. Nós, os refugiados. Covilhã: Universidade da Beira, 2013.

BENJAMIN, W. Obras escolhidas volume 1: magia e técnica, arte e

política. São Paulo: Brasiliense, 2008.

BUTLER, J. Precarious life: the powers of mourning and violence. New York: Verso, 2004.

DELEUZE, G. A imagem-tempo. São Paulo: Editora Brasiliense, 2009.

Sobre as Sociedades de Controle Post-Scriptum. In: DELEUZE, Gilles. Conversações. São Paulo: Editora 34, 1992.

DIDI-HUBERMAN, G. Images malgré tout. Paris: Les Éditions de Minuit, 2003.

. Pueblos expuestos, pueblos figurantes. Buenos Aires: Ediciones Manantial, 2014.

Sobrevivência dos vaga-lumes. Belo Horizonte: Editora UFMG, 2011.

. Quando as imagens tocam o real. In: Pós. Belo Horizonte:, EBA UFMG, v. 2, n. 4, p. 204-219, 2012.

GILROY, P. O Atlântico negro. São Paulo: Editora 34, 2017.

GLISSANT, E. Creolization in the Making of the Americas. In: Caribbean Quarterly, v. 54, n.1-2. p. 81-89, 2008.

Poetics of relation. University of Michigan Press, 1997.

HAESBAERT, R. O mito da desterritorialização: do "fim dos territórios" à multiterritorialidade. Rio de Janeiro: Bertrand Brasil, 2016.

MBEMBE, A. Crítica da Razão Negra. Lisboa: Antígona, 2014.

Necropolitics. Public Culture, Duke University Press. 2003, p. 11-40.

MIGNOLO, W. D. Colonialidade: O lado mais escuro da modernidade. In: BCS, v. 32, n. 94, jun. 2017.

. A colonialidade de cabo a rabo: o hemisfério ocidental no horizonte conceitual da modernidade. CLASCO, Consejo Latinoamericano de Ciencias Sociales, 2005.

Histórias locais - projetos globais: colonialidade, saberes subalternos e pensamento liminar. Belo Horizonte: Ed. UFMG, 2003.

OLIVEIRA, C. História desenterrada. O Globo, 2017. Disponível em: https://oglobo. globo.com/sociedade/historia-desenterrada-21532191. Acesso em: fev. 2019.

QUIJANO, A. A colonialidade do saber: eurocentrismo e ciências sociais. Perspectivas latino-americanas. CLACSO, Consejo Latinoamericano de Ciencias Sociales, 2005.

RANCIÈRE, Jacques. O inconsciente estético. São Paulo: Ed. 34, 2009.

Politics, Identification, and Subjectivization. In: The Identity in Question. The MIT Press, v. 61, p. 58-64. October, 1992.

ROGOFF, I. Terra infirma: geography's visual culture. New York: Routledge, 2006.

SERRES, M.. Narrativas do humanismo. Rio de Janeiro: Bertrand Brasil, 2015.

VASSALLO, S. Entre objetos da ciência e vítimas de um holocausto negro: humanização, agência e tensões classificatórias em torno das ossadas do sítio arqueológico 
Cemitério dos Pretos Novos. Interseções - Revista de Estudos Interdisciplinares, v. 20, p. 36-66, 2018.

. Entre vidas objetificadas e vítimas da escravização: a trajetória das ossadas do Cemitério dos Pretos Novos no Rio de Janeiro. Sexualidad, Salud y Sociedad, Rio de Janeiro, p.277-297, 2017.

\section{Filmes}

A CHAVE da casa. Direção: Stela Grisoti e Paschoal Samora. Brasil, 2009.

BLOOD in the Mobile. Direção: Frank Piasecki Poulsen. Dinamarca/Alemanha, 2010. TV (52 min).

ERA o HOTEL Cambridge. Direção: Eliane Caffé. São Paulo: Aurora Filmes, 2016. 1 DVD (93 min),

\section{Sobre os autores}

Fernando Antônio Resende - Professor do curso de Estudos de Mídia e do Programa de Pós-Graduação em Comunicação do Departamento de Mídia e Estudos Culturais da Universidade Federal Fluminense (UFF) e professor da Cátedra João Guimarães Rosa de Estudos Culturais e da Comunicação no Brasil (Universität Tübingen, Alemanha). Coordenador do Programa de Pós-Graduação em Comunicação (PPGCOM/UFF). Doutor em Ciências da Comunicação pela Universidade de São Paulo (2002), Pós-doutorado na School of Oriental and African Studies (SOAS University of London - Inglaterra - 2013), mestre em Estudos Literários pela Universidade Federal de Minas Gerais (1995) e graduado em Comunicação Social - Jornalismo pela Pontifícia Universidade Católica de Minas Gerais (1988). No presente artigo, o autor participou da concepção do desenho da pesquisa, do desenvolvimento da discussão teórica, da coleta e interpretação dos dados, da redação do manuscrito e da revisão do texto.

Roberto Robalinho - Pós-doutorando em Comunicação no Programa de Pós- Graduação em Comunicação no Instituto de Artes e Comunicação Social da UFF. Participou do programa de pós-doutorado de excelência Teach@ Tübingen na Universidade de Tübingen como professor visitante. Doutor 
500 QUANDO A IMAGEM É CORPO: MODOS DE SOBREVIVER À MÁQUINA COLONIAL

em Comunicação pelo PPGCOM-UFF, mestre pelo PPGCOM-UFF. No presente artigo, o autor participou da concepção do desenho da pesquisa, do desenvolvimento da discussão teórica, da coleta e interpretação dos dados, da redação do manuscrito e da revisão do texto.

Diego Granja Amaral - Doutorando do Programa de Pós-Graduação em Comunicação da Universidade Federal Fluminense (UFF) em cotutela com a Universidade de Tübingen (EKUT), Alemanha. Mestre em Comunicação pela Universidade Federal de Pernambuco. No presente artigo, o autor participou da concepção do desenho da pesquisa, do desenvolvimento da discussão teórica, da coleta e interpretação dos dados, da redação do manuscrito e da revisão do texto.

Data de submissão: 12/08/2019

Data de aceite: 04/10/2019 